\title{
LEGALIDADE ADMINISTRATIVA E CONTROLE DA LITIGIOSIDADE DO PODER PÚBLICO ${ }^{1}$
}

THE ADMINISTRATIVE PRINCIPLE OF LEGALITY AND STATE CONTROL OF LITIGATION LEGALIDAD ADMINISTRATIVA Y CONTROL DE LA LITIGIOSIDAD DEL PODER PÚBLICO

Claudio Madureira²

Resumo: Neste artigo, procuro relacionar o problema da litigiosidade no processo à (má) aplicação do Direito pelo poder público. Tomo como ponto de partida para minha análise o hiato verificado, por observação empírica, entre a prática e a teoria, isto é, entre a imposição jurídico-normativa a que os agentes públicos apliquem corretamente o Direito (ínsita à noção de legalidade administrativa) e a verificação casuística de que, por vezes, essa tarefa não é exercida a contento.

1 Este trabalho foi concebido no contexto de pesquisa financiada pela Fundação de Amparo à Pesquisa e Inovação do Espírito Santo - FAPES (Edital nº 06/2015 - UNIVERSAL INDIVIDUAL), que estuda "A conciliação como meio alternativo para a resolução de controvérsias jurídicas envolvendo a Fazenda Pública".

2 Doutor em Direito pela Pontifícia Universidade Católica de São Paulo - PUC/SP, Mestre em Direito Processual pela Universidade Federal do Espírito Santo - UFES, Professor do Programa de Pós-Graduação em Direito da Universidade Federal do Espírito Santo - UFES (Mestrado em Direito), Procurador do Estado do Espírito Santo e Advogado. E-mail: madureira. fmr@gmail.com. 
Palavras-chave: Direito Constitucional. Direito Administrativo. Direito Processual Civil. Legalidade. Litigiosidade. Interesse Público.

Abstract: This article aims to link the problem of litigation in the lawsuit to the (mis)application of the law by the state. I take as a starting point for my analysis the gap observed, through empirical observation, between practice and theory, i.e. between the rules imposed by public agents who properly apply the law (inherent to the concept of administrative legality) and the casuistry verification, a task that is not always performed satisfactorily.

Keywords: Constitutional Right. Administrative Law. Civil Procedure. Legality. Litigation. Public Interest.

Resumen: En este artículo procuro relacionar el problema de la litigiosidad en el proceso a la (mala) aplicación del Derecho por el poder público. Tomo como punto de partida para mi análisis el hiato verificado, por observación empírica, entre la práctica y la teoría, es decir entre la imposición jurídico normativa de que los agentes públicos apliquen correctamente el Derecho (ínsita a la noción de legalidad administrativa) y la verificación casuística de que a veces esa tarea no se ejerce satisfactoriamente.

Palabras clave: Derecho Constitucional. Derecho Administrativo. Derecho Procesal Civil. Legalidad. Litigiosidad. Interés Público.

\section{EXPOSIÇÃO DO PROBLEMA}

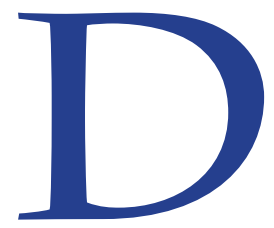

almo de Abreu Dallari conceitua o Estado como "ordem jurídica soberana que tem por fim o bem comum de um povo situado em um território"3_4. Ora, se o Estado, como institucionalização política de uma sociedade, resulta de uma ordem jurídica, por óbvio não lhe assiste, sob qualquer perspectiva, desafiá-la. Destarte, a sua atuação frente à sociedade pressupõe atenção aos limites que lhe atribui essa mesma ordem jurídica. Afinal, como ensina Maria Sylvia Zanella Di Pietro, "a lei [...] estabelece

3 DALLARI, Dalmo de Abreu. Elementos de Teoria Geral do Estado. 20. ed. São Paulo: Saraiva, 1998. p. 118.

4 Sobre a argumentação que se segue, cf.: MADUREIRA, Claudio. Advocacia Pública. Belo Horizonte: Fórum, 2015 (no prelo). Capítulo 1. 
também os limites da atuação administrativa que tenha por objeto a restrição ao exercício de [...] direitos em benefício da coletividade" ${ }^{\prime 5}$.

Disso decorre a noção de legalidade, que, na feliz observação de Celso Antônio Bandeira de Mello, traduz o propósito político "de submeter os exercentes do poder em concreto - o administrativo - a um quadro normativo que embargue favoritismos, perseguições e desmandos" ${ }^{\prime 6}$. Até porque, como lecionam Eduardo García de Enterría e Tomás-Ramón Fernández, "a legalidade a que a Administração está sujeita é antes de tudo uma técnica para garantir a liberdade", de tal sorte que "a violação à legalidade que leve o cidadão a suportar o que a lei não permite é uma agressão à sua liberdade e sua oposição a isto é uma defesa dela"7.

Nessa senda, Bandeira de Mello acentua que "através da norma geral, abstrata e por isso mesmo impessoal", isto é, da "lei, editada, pois, pelo Poder Legislativo que é o colégio representativo de todas as tendências (inclusive minoritárias) do corpo social", pretendeu-se "garantir que a atuação do Executivo nada mais seja senão a concretização dessa vontade geral"8. Por esse motivo é que os agentes públicos têm a sua atuação vinculada aos estritos limites do que lhes determinam a lei e a Constituição. Cumpre-Ihes, pois, em suas atividades cotidianas, aplicar corretamente o Direito, servindo, assim, aos interesses juridicizados pelos legítimos representantes do povo.

Ocorre que, dia após dia, ações judiciais são propostas por particulares em face do poder público, justamente sob a invocação de hipotética negativa de fruição a direitos subjetivos fundados em regras e princípios que compõem o ordenamento jurídico-positivo; sendo que, como mostra a experiência, diversas dessas demandas são solucionadas pelo Poder Judiciário contrariamente às posições nelas sustentadas pelos entes estatais ${ }^{9}$. Depreendo, então, em concreto,

5 DI PIETRO, Maria Sylvia Zanella. Direito Administrativo. 13. ed. São Paulo: Atlas, 2001. p. 67.

6 MELLO, Celso Antônio Bandeira de. Curso de Direito Administrativo. 27. ed. São Paulo: Malheiros, 2010. p. 100.

7 ENTERRÍA, Eduardo García de; FERNÁNDEZ, Tomás-Ramón. Curso del Derecho Administrativo, vol. II. 11. ed. Madri, Thomson Civitas, 2008. p. 48; apud MELLO, Celso Antônio Bandeira de. A noção jurídica de "interesse público". In: MELLO, Celso Antônio Bandeira de. Grandes temas de direito administrativo. São Paulo: Malheiros, 2010. p. 186.

8 MELLO, Celso Antônio Bandeira de. Curso de Direito Administrativo, cit., p. 100.

9 Quanto ao particular, Luciane Moessa de Souza leciona que "quando o Poder Executivo não cumpre os seus deveres estatuídos em lei, há muito se admite a necessidade e conveniên- 
um hiato entre a prática e a teoria, isto é, entre a imposição jurídico-normativa a que os agentes públicos apliquem corretamente o Direito e a verificação casuística de que, por vezes, essa tarefa administrativa não é exercida a contento.

Clovis Beznos certa feita expressou que, se o Estado de Direito pressupõe a efetividade do Direito e o respeito à Constituição, dispondo, a propósito, que quando essa expectativa não se realizar, "é papel do jurista identificar os mecanismos de defesa do Estado de Direito, para que o Direito, em sua dinâmica, seja efetivo"10. A isso me proponho neste artigo, em que tomo por objeto de análise o relacionamento entre o problema da litigiosidade e a (má) aplicação do Direito pelo poder público.

\section{O PODER PÚBLICO COMO AGENTE INDUTOR DA LITIGIOSIDADE NO PROCESSO E DA MOROSIDADE DA JUSTIÇA}

Luciane Moessa de Souza leciona que "qualquer estudo sério sobre os entraves ao acesso à justiça no Brasil depara-se com a constatação de que o obstáculo mais criticado é a morosidade"11_12. Esse obstáculo, por sua vez, "encontra-se ligado, entre outros fatores, ao grande número de feitos levados ao Judiciário", isto é, ao problema da litigiosidade ${ }^{13}$. Mas o que mais impressiona quando se

cia da atuação do Poder Judiciário - aí entra o já tradicional controle jurisdicional da atividade administrativa, mormente quando ela se manifesta por uma ação positiva que afronte a previsão legal, mas também por omitir-se o administrador na realização dos deveres previstos em lei -, sendo que já ficou consagrado que o dogma da separação dos poderes deve ceder ante a necessidade de império do Direito" (SOUZA, Luciane Moessa de. Consultoria jurídica no exercício da advocacia pública: a prevenção como melhor instrumento para a concretização dos objetivos do Estado brasileiro. In: GUEDES, Jefferson Carús; SOUZA, Luciane Moessa de (Coord.). Advocacia de Estado: questões institucionais para a construção de um Estado de justiça. Belo Horizonte: Fórum, 2009. p. 170).

10 BEZNOS, Clovis. Aspectos jurídicos da indenização na desapropriação. Belo Horizonte: Fórum, 2010. p. 15.

11 SOUZA, Luciane Moessa de. Autonomia institucional da advocacia pública funcional de seus membros: instrumentos necessários para a concretização do Estado Democrático de Direito. In: GUEDES, Jefferson Carús; SOUZA, Luciane Moessa (Coord.). Advocacia de Estado: questões institucionais para a construção de um Estado de justiça. Belo Horizonte: Fórum, 2009. p. 91.

12 Sobre a argumentação que se segue, cf.: MADUREIRA, Claudio. Advocacia Pública, cit., Tópico 1.1 do Capítulo 1.

13 SOUZA, Luciane Moessa de. Autonomia institucional da advocacia pública funcional de seus membros: instrumentos necessários para a concretização do Estado Democrático de Direito, cit., p. 91. 
enfoca essa questão é a constatação de que "o Poder Publico é, de longe, o litigante mais frequente em juízo"14_15.

Essa constatação empírica fez com que Kazuo Watanabe reconhecesse no Estado brasileiro um grande gerador de $\operatorname{conflitos}^{16}$. O processualista destaca, a propósito, que parte considerável das várias demandas que diariamente afluem ao Poder Judiciário apresenta num dos polos, principalmente no polo passivo, na condição de réu, o Estado ou uma de suas emanações (autarquias, empresas públicas, ou sociedades de economia mista) ${ }^{17}$. Quanto ao particular, Pierpaolo Cruz Bottini, então Secretário-Chefe da Secretaria da Reforma do Judiciário instituída no âmbito do Ministério da Justiça, relatou, em texto acadêmico, que, conquanto no Brasil exista um processo em tramitação para cada dez brasileiros, o que sugere que, entre nós, os mecanismos de acesso ao Judiciário funcionariam muito bem, esse "alto índice de litigância no Judiciário brasileiro aponta apenas que um número muito pequeno de pessoas ou instituições utilizam intensamente o sistema, enquanto que a maior parte da população não tem acesso a este meio formal de resolução de conflitos", para concluir, adiante, que o que vivenciamos, na verdade, não é "a democratização do acesso à justiça, mas a sua utilização exagerada por poucos atores, dentre os quais o Poder Público"18_19.

Nesse mesmo sentido se pronunciaram, em evento público, o Vice-Presidente da República, Michel Temer, e o Ministro da Justiça, José Eduardo Cardozo, como retrata notícia publicada no portal do Conselho Nacional de Justiça em 21 de março

14 SOUZA, Luciane Moessa de. Autonomia institucional da advocacia pública funcional de seus membros: instrumentos necessários para a concretização do Estado Democrático de Direito, cit., p. 91.

15 Nesse mesmo sentido se manifesta Danilo Cruz Madeira (MADEIRA, Danilo Cruz. O papel da Advocacia Pública no Estado Democrático de Direito. Revista Virtual da AGU, ano 10, n. 107, dez. 2010. Disponível em: <http://www.agu.gov.br/sistemas/site/TemplateImagem Texto Thumb.aspx?idConteudo $=152998 \& i d \_s i t e=1115 \&$ ordenacao $=1>$. Acesso em: 23 out. 2012. p. 02).

16 WATANABE, Kazuo. O acesso à justiça e a sociedade moderna. In: GRINOVER, Ada Pellegrini, DINAMARCO, Cândido Rangel; WATANABE, Kazuo (Coord.). Participação e processo. São Paulo: Revista dos Tribunais, 1988. p. 130.

17 WATANABE, Kazuo. O acesso à justiça e a sociedade moderna, cit., p. 130-131.

18 BOTTINI, Pierpaolo Cruz. A Justiça do Trabalho e a reforma do Judiciário. In: CHAVES, Luciano Athayde (Org.). Direito processual do trabalho: reforma a efetividade. São Paulo: LTr, 2007. p. 102.

19 Sobre o assunto, ler também: MADUREIRA, Claudio Penedo. Poder público, litigiosidade e responsabilidade social, cit. 
de $2011^{20}$. Temer observou, na oportunidade, que "um dos grandes geradores de processos na Justiça é o Executivo"21. Cardozo, por sua vez, criticou a litigiosidade excessiva gerada pela Administração Pública e salientou a importância de se promover o maior acesso à justiça no Brasil, dispondo, a propósito, que "se de um lado temos a litigiosidade do Estado com a sociedade, que abarrota os tribunais, de outro temos muitos brasileiros afastados da prestação jurisdicional, com direitos violados que não são levados à Justiça"22.

Isso ocorre porque o Estado é elemento orgânico da institucionalização política de uma sociedade, e por isso sustenta numerosas responsabilidades e pretensões, que o conduzem, cotidianamente, aos litígios judiciais; mas também porque comumente se supõe que competiria aos agentes estatais, em vista do conteúdo do princípio da indisponibilidade do interesse público, a defesa incondicional do erário, ao passo que cumpriria aos advogados públicos, como profissionais de atividade jurídica vinculada, posicionarem-se contrariamente às suas convicções jurídicas, sustentando o insustentável, ou contestando o incontestável, como forma de legitimar opções políticas e administrativas preconcebidas pelos governantes e demais gestores públicos, num contexto em que não lhes caberia dispor sobre direitos e interesses deduzidos em juízo pelo poder público. Essa situação é representada com exatidão na seguinte passagem da obra de Di Pietro:

A regra é que as autoridades administrativas, mesmo quando revelam inconformismo com a submissão à lei e ao Direito - que muitas vezes constituem entraves aos seus objetivos - consultam a advocacia pública, ainda que a lei não exija sempre essa consulta. É interessante que, mesmo quando quer praticar um ato ilícito, a autoridade quer fazê-lo com base em parecer dado pelo órgão jurídico; para esse fim, ela pede, pressiona, exige um parecer que lhe convenha. Ela quer, na realidade, dar uma aparência de legalidade a um ato ilegal; e, para esse fim, quer refugiar-se atrás de um

20 Disponível na internet: http://www.cnj.jus.br/atos-administrativos/13613:ministro-pelusopropoe-medida-para-combater-morosidade-gerada-por-excesso-de-recursos. Acesso em: 13 de maio de 2013.

21 Disponível na internet: http://www.cnj.jus.br/atos-administrativos/13613:ministro-pelusopropoe-medida-para-combater-morosidade-gerada-por-excesso-de-recursos. Acesso em: 13 de maio de 2013.

22 Disponível na internet: http://www.cnj.jus.br/atos-administrativos/13613:ministro-pelusopropoe-medida-para-combater-morosidade-gerada-por-excesso-de-recursos. Acesso em: 13 de maio de 2013. 
parecer jurídico. Na hora da responsabilidade, poderá proteger-se com a escusa de que agiu com base em parecer do órgão jurídico ${ }^{23}$.

Todavia, semelhante inclinação teórica representa outro daqueles inconscientes coletivos que, por vezes, se instalam nas mentes dos intérpretes (aplicadores), e que culminam por afetar o Direito, no campo de sua aplicação, prejudicando a sua realização, até que descobertos e subjugados pelo debate científico.

Afinal, como observa, noutro trabalho, Luciane Moessa de Souza, o Estado "como fonte praticamente exclusiva da emanação de normas jurídicas de cunho geral, [...] deveria ser o primeiro a dar o exemplo no seu cumprimento" 24 . Se atuasse desse modo, "além de contribuir para reduzir a morosidade do Judiciário", o poder público "contribuiria também para despertar uma maior confiabilidade nas instituições oficiais, instaurando um clima tão propício, seja para o desenvolvimento em sentido meramente econômico, seja para o desenvolvimento de uma sociedade em sentido amplo"25.

\section{LEGALIDADE, LEGALIDADE ADMINISTRATIVA E VINCULAÇÃO DOS AGENTES ESTATAIS AO DIREITO}

Em rigor, não resta alternativa ao Estado brasileiro ${ }^{26}$. Com efeito, o agente estatal, na lição de Hely Lopes Meirelles, "não pode [...] deixar de cumprir os deveres que a lei lhe impõe, nem renunciar a qualquer parcela dos poderes e prerrogativas que lhes são conferidos", precisamente porque "os deveres, poderes e prerrogativas não lhe são outorgados em consideração pessoal, mas sim, para serem utilizados em benefício da comunidade administrada"27. Daí falar-se em legalidade estrita, a vincular a Administração Pública e seus agentes,

23 DI PIETRO, Maria Sylvia. Advocacia Pública. Revista Jurídica da Procuradoria Geral do Município de São Paulo, São Paulo, n. 3, p. 11-30, dez 1996. p. 18.

24 SOUZA, Luciane Moessa de. Consultoria jurídica no exercício da advocacia pública: a prevenção como melhor instrumento para a concretização dos objetivos do Estado brasileiro, cit., p. 167.

25 SOUZA, Luciane Moessa de. Consultoria jurídica no exercício da advocacia pública: a prevenção como melhor instrumento para a concretização dos objetivos do Estado brasileiro, cit., p. 167.

26 Sobre a argumentação que se segue, cf.: MADUREIRA, Claudio. Advocacia Pública, cit., Tópico 1.2 do Capítulo 1.

27 MEIRELLES, Hely Lopes. Direito Administrativo Brasileiro. 16. ed. São Paulo: Revista dos Tribunais, 1991. p. 77. 
que, conforme observa Celso Antônio Bandeira de Mello, é "fruto da submissão do Estado à lei"28; e que se encontra positivada, entre nós, como princípio de sede constitucional, na medida em que restou assentada pelo poder constituinte originário no caput do artigo 37 da Constituição ${ }^{29}{ }^{30}$.

Maria Sylvia Zanella Di Pietro destaca a absoluta importância da legalidade para o regime jurídico-administrativo, quando afirma que "este princípio juntamente com o de controle da Administração pelo Poder Judiciário, nasceu com o Estado de Direito e constitui uma das principais garantias de respeito aos direitos individuais"31. Nesse mesmo sentido se posiciona Romeu Felipe Bacellar Filho, quando expõe que esse princípio decorre "do Estado de Direito, respeitadas as nuances da construção do significado desse conceito em cada país"32. Trata-se, pois, como ensinam José Joaquim Gomes Canotilho e Vital Moreira, de "instrumento normativo de vinculação jurídico-constitucional da Administração" ${ }^{\prime 3}$.

Por força desse princípio é que, na preciosa observação de Meirelles, "enquanto na administração particular é lícito fazer tudo o que a lei não proíbe, na Administração Pública só é permitido fazer o que a lei autoriza" ${ }^{34}$. Ou, como expressa Bandeira de Mello, "ao contrário dos particulares, os quais podem fazer tudo que não Ihes seja proibido, a Administração pode fazer apenas o que lhe seja de antemão permitido por lei"35_36. Ou, ainda, como sintetiza Di Pietro, "a Administração Pública só pode fazer o que a lei permite" ${ }^{137}$.

28 MELLO, Celso Antônio Bandeira de. Curso de Direito Administrativo, cit., p. 100.

29 CRFB. "Art. 37. A administração pública direta e indireta de qualquer dos Poderes da União, dos Estados, do Distrito Federal e dos Municípios obedecerá aos princípios de legalidade, impessoalidade, moralidade, publicidade e eficiência e, também, ao seguinte: (Redação dada pela Emenda Constitucional no 19, de 1998)" (destaques pessoais).

30 Cf.: BACELLAR FILHO, Romeu Felipe. A noção jurídica de interesse público no direito administrativo brasileiro. In: BACELLAR FILHO, Romeu Felipe; HACHEM, Daniel Wunder (Coord.). Direito administrativo e interesse público: estudos em homenagem ao Professor Celso Antônio Bandeira de Mello. Belo Horizonte: Fórum, 2010. p. 96.

31 DI PIETRO, Maria Sylvia Zanella. Direito Administrativo, cit., p. 67.

32 BACELLAR FILHO, Romeu Felipe. A noção jurídica de interesse público no Direito Administrativo Brasileiro, cit., p. 96.

33 CANOTILHO, José Joaquim Gomes de; MOREIRA, Vital. Fundamentos da Constituição. Coimbra: Coimbra Editora, 1991. p. 84.

34 MEIRELLES, Hely Lopes. Direito Administrativo Brasileiro, cit., p. 78.

35 MELLO, Celso Antônio Bandeira de. Legalidade, discricionariedade: seus limites e controle. In: MELLO, Celso Antônio Bandeira de. Grandes temas de direito administrativo. São Paulo: Malheiros, 2010. p. 57.

36 Sobre o assunto, consulte-se, ainda: MELLO, Celso Antônio Bandeira de. Curso de Direito Administrativo, cit., p. 76 e 101.

37 DI PIETRO, Maria Sylvia Zanella. Direito Administrativo, cit., p. 68. 
Postos esses contornos gerais, Bacellar Filho chama a atenção para importante debate travado no plano da Ciência, que consiste em investigar se o princípio da legalidade vincula a Administração ao ordenamento jurídico como um todo ou exclusivamente à lei em sentido formal ${ }^{38}$. Em suas próprias palavras, "o princípio da legalidade conduz à formação da relação de legalidade entre os atos administrativos, de um lado, e o sistema jurídico (concepção ampla)" ou entre eles e "a lei em sentido formal (concepção estrita), do outro"39. Assim, ao lado de uma acepção restritiva de legalidade, que relaciona esse princípio tão somente ao que prescrevem as leis administrativas, construiu-se, conforme Bacellar Filho, uma acepção mais ampla, que vincula a Administração e seus agentes ao ordenamento jurídico em sua integralidade, isto é, às leis e também à Constituição.

Segundo Bacellar Filho, aderem a essa acepção mais ampla de legalidade (legalidade como conformação à integralidade do ordenamento jurídico, inclusive à Constituição) Lúcia Valle de Figueiredo ${ }^{40}$, Odete Medauar ${ }^{41}$ e Carmen Lúcia Antunes Rocha ${ }^{42}{ }^{43}$. Como forma de explicitá-la, o publicista procura sintetizar o pensamento de Carmen Lúcia Rocha ${ }^{44}$, observando, quanto ao particular, que para essa professora mineira, "o princípio da legalidade [...] conserva o nome de legalidade, embora signifique, hoje, juridicidade, de sorte que quando a Constituição refere-se à legalidade [...] deve-se ler juridicidade"45.

Bacellar Filho manifesta a sua adesão à acepção mais restrita de legalidade (legalidade como conformação apenas às leis), também sustentada, entre

38 BACELLAR FILHO, Romeu Felipe. A noção jurídica de interesse público no Direito Administrativo Brasileiro, cit., p. 96.

39 BACELLAR FILHO, Romeu Felipe. A noção jurídica de interesse público no Direito Administrativo Brasileiro, cit., p. 96.

40 FIGUEIREDO, Lúcia Valle. Processo e procedimento administrativo. In: FIGUEIREDO, Lúcia Valle. Perspectivas do direito público. Belo Horizonte: Del Rey, 1995.

41 MEDAUAR, Odete. O direito administrativo em evolução. São Paulo: Revista dos Tribunais, 1992.

42 Cf.: ROCHA, Carmen Lúcia Antunes. O princípio constitucional da igualdade. Belo Horizonte: Lê, 1990 e ROCHA, Carmen Lúcia Antunes. Princípios constitucionais da Administração Pública. Belo Horizonte: Del Rey, 1994.

43 BACELLAR FILHO, Romeu Felipe. A noção jurídica de interesse público no Direito Administrativo Brasileiro, cit., p. 96-97.

44 ROCHA, Carmen Lúcia Antunes. O princípio constitucional da igualdade, cit., p. 7879, 81, 84.

45 BACELLAR FILHO, Romeu Felipe. A noção jurídica de interesse público no Direito Administrativo Brasileiro, cit., p. 97. 
nós ${ }^{46}$, por Maria Sylvia Di Pietro ${ }^{47}$. Esse professor paranaense defende que "a adoção do sentido restrito do princípio da legalidade é exigência da própria Constituição", à consideração de que "se o princípio da legalidade pretendesse abarcar a própria vinculação constitucional da atividade administrativa seria inútil e totalmente despida de sentido a afirmação dos outros princípios constitucionais da Administração Pública"48. E observa, em arremate, que "a adoção de conceito amplo faz confundir legalidade e constitucionalidade", pervertendo-se "a hierarquia das fontes do direito (são colocados no mesmo plano blocos distintos da pirâmide normativa) quando no sistema constitucional brasileiro estão, rigidamente, delimitados"49. Daí que, em sua opinião, a atividade administrativa pressupõe "a observância de ambos os princípios: legalidade (em sentido estrito), como cumprimento da lei formal, e juridicidade, como atendimento aos mandamentos do ordenamento jurídico como um todo, sobretudo das normas constitucionais"

De toda sorte, deixando de lado por essa dissensão teórica mencionada por Bacellar Filho, cuja pacificação demandaria estudo específico, importa destacar em vista dos limites da discussão proposta neste trabalho, que se circunscreve à descrição da relação existente entre o problema da litigiosidade e a (má) aplicação do direito pelo poder público - que a Administração e seus agentes também se encontram vinculados, entre nós, aos enunciados prescritivos que compõem o texto constitucional, e que devem, por isso, quando de sua referência às leis, interpretá-las e aplicá-las em consonância com a Constituição.

\section{À GUISA DE CONCLUSÃO: ABSOLUTA VINCULAÇÃO DOS AGENTES ESTATAIS À REALIZAÇÃO DE INTERESSES PRIMÁRIOS}

As razões até aqui expostas põem a salvo de quaisquer dúvidas que a atividade administrativa desenvolvida pelos agentes estatais quando se propõem a defender

46 BACELLAR FILHO, Romeu Felipe. A noção jurídica de interesse público no Direito Administrativo Brasileiro, cit., p. 97-98.

47 DI PIETRO, Maria Sylvia Zanella. Direito Administrativo, cit., p. 61.

48 BACELLAR FILHO, Romeu Felipe. A noção jurídica de interesse público no Direito Administrativo Brasileiro, cit., p. 99.

49 BACELLAR FILHO, Romeu Felipe. A noção jurídica de interesse público no Direito Administrativo Brasileiro, cit., p. 99.

50 BACELLAR FILHO, Romeu Felipe. A noção jurídica de interesse público no Direito Administrativo Brasileiro, cit., p. 99. 
o erário, assim como aquela desempenhada pelos advogados públicos quando atuam na consultoria jurídica e nas ações judiciais em que toma parte o poder público, deve ser exercida com o propósito de aplicar as leis e a Constituição, possibilitando, assim, a integral fruição dos direitos subjetivos assegurados pelo ordenamento jurídico-positivo ${ }^{51}$. Afinal, como assevera Maria Sylvia Zanella Di Pietro, "os poderes atribuídos à Administração têm o caráter de poder-dever; são poderes que ela não pode deixar de exercer, sob pena de responder pela omissão"52. A propósito, Clovis Beznos critica o emprego da expressão poder-dever, recomendando a sua substituição pela expressão dever-poder, à consideração de que "a Administração, na competência que lhe é atribuída para curar dos interesses públicos, de onde lhe decorre um poder de agir, tem em contrapartida um dever de atuar, configurando antes tal atribuição um dever-poder, do que um poder-dever" 53 . Mas é certo que, sob uma ou outra designação, "a autoridade não pode renunciar ao exercício das competências que lhe são outorgadas por lei", pois a "cada vez que ela se omite no exercício dos seus poderes, é o interesse público que está sendo prejudicado" ${ }^{54}$, como expressa Di Pietro em arremate.

Destarte, os agentes estatais devem cultivar, em suas atividades cotidianas, uma correta aplicação do Direito; mesmo quando, em concreto, dela puder resultar contrariedade a interesses transitoriamente defendidos pelo poder público, comumente designados como interesses secundários, segundo a classificação proposta por Renato Alessi ${ }^{55}$. Esses interesses não se apresentam como legítima expressão do interesse público, mas se qualificam, simplesmente, como interesses particulares do Estado, na locução empregada por Celso Antônio Bandeira de Mello ${ }^{56}$, e por isso apenas se revestem dessa condição (de interesse público) quando instrumentais à realização de interesses ditos primários.

51 Sobre a argumentação que se segue, cf.: MADUREIRA, Claudio. Advocacia Pública, cit., Tópico 1.3 do Capítulo 1.

52 DI PIETRO, Maria Sylvia Zanella. Direito Administrativo, cit., p. 70.

53 BEZNOS, Clovis. Procuradoria Geral do Estado e defesa dos interesses públicos. Revista de Direito Público, São Paulo: Revista dos Tribunais, ano 23, n. 93, jan./mar. 1990. p. 138.

54 DI PIETRO, Maria Sylvia Zanella. Direito Administrativo, cit., p. 70.

55 Cf.: ALESSI, Renato. Sistema instituzionale del diritto amministrativo italiano. 3. ed. Milão: Giuffrè, 1960. p. 197.

56 MELLO, Celso Antônio Bandeira de. A noção jurídica de "interesse público". In: MELLO, Celso Antônio Bandeira de. Grandes temas de direito administrativo. São Paulo: Malheiros, 2010. p. 188. 
Por esse motivo, não prospera a ilação de que é missão dos servidores públicos, em especial daqueles que integram a Advocacia Pública, tão somente "a defesa do interesse público secundário (apenas do Estado), ao passo que ao Ministério Público é que caberia, com exclusividade, a defesa do interesse público primário (da sociedade)", como denuncia Luciane Moessa de Souza ${ }^{57}$. Luís Roberto Barroso parece aderir a essa compreensão criticada pela publicista; como depreendemos da seguinte passagem doutrinária:

A noção de interesse público, para os fins aqui visados, irá utilizar uma distinção fundamental e pouco explorada, que o divide em primário e secundário. O interesse público primário é a razão de ser do Estado e sintetiza-se nos fins que cabe a ele promover: justiça, segurança e bem-estar social. Estes são interesses de toda a sociedade. O interesse público secundário é o da pessoa jurídica de direito público que seja parte em uma determinada relação jurídica - quer se trate da União, do Estado-membro, do Município ou das suas autarquias. Em ampla medida, pode ser identificado como interesse do erário, que é o de maximizar a arrecadação e minimizar as despesas.

Embora não tenha sido objeto de elaboração doutrinária mais densa, conforme registrado acima, essa distinção não é estranha à ordem jurídica brasileira. É dela que decorre, por exemplo, a conformação constitucional das esferas de atuação do Ministério Público e da Advocacia Pública. Ao primeiro cabe a defesa do interesse público primário; à segunda, a do interesse público secundário ${ }^{58}$.

Ocorre que, como bem observa Marçal Justen Filho, "o Estado não pode ludibriar, espoliar ou prevalecer-se da fraqueza ou da ignorância alheia", porque "o interesse público não reside em obter lucro, se tal se fizer através de atividades especulares, de duvidosa valia ética"59. Destarte, os agentes estatais, com destaque para a atuação da Advocacia Pública, devem perseguir, sempre, a realização do interesse público primário, de modo a assegurar aos

57 SOUZA, Luciane Moessa de. Autonomia institucional da advocacia pública funcional de seus membros: instrumentos necessários para a concretização do Estado Democrático de Direito, cit., p. 100.

58 BARROSO, Luís Roberto. Prefácio. In: SARMENTO, Daniel (Org.). Interesses públicos versus interesses privados: desconstruindo o princípio da supremacia do interesse público. Rio de Janeiro: Lumen Juris, 2005. p. xiii-xiv.

59 JUSTEN FILHO, Marçal. Conceito de interesse público e a "personalização" do direito administrativo. Revista Trimestral de Direito Público, n. 26, 1999. p. 118. 
administrados a integral fruição dos direitos subjetivos que lhes são assegurados pelo ordenamento jurídico-positivo. Até porque, pelas razões dantes expostas, outra alternativa não Ihes confere o princípio da legalidade administrativa, minudenciado nos tópicos precedentes.

Em rigor, sequer se justifica falarmos em interesse público secundário. A propósito da distinção teórica entre interesses primários e secundários, Ricardo Marcondes Martins observa, reportando-se diretamente à doutrina de Alessi60, que o interesse primário corresponde ao "complexo de direitos individuais prevalentes em uma determinada organização jurídica da coletividade", ao passo que o interesse secundário comporta "o interesse da administração enquanto aparato organizativo, unitariamente considerado"61. Entre nós, essa distinção foi propagada por Bandeira de Mello, para quem o interesse primário qualifica-se como dimensão pública dos interesses individuais, porque se refere ao plexo de interesses dos indivíduos como partícipes da sociedade, ao passo que o interesse secundário é o interesse particular (ou individual) do Estado, como pessoa jurídica autônoma62_63. De todo modo, tanto Alessi quanto Bandeira de Mello "insistiram numa observação importantíssima", ao enunciarem que "o interesse secundário só pode ser perseguido pela Administração quando for coincidente com o primário"64, como destaca Martins na sequência.

Martins observa, ainda, que "a partir da lição de Alessi, parte de doutrina passou a defender a existência de interesses públicos disponíveis, justamente

60 Nas palavras de Alessi, oportunamente trascritas por Martins (MARTINS, Ricardo Marcondes. Arbitragem e administração pública: contribuição para o sepultamento do tema. Revista Trimestral de Direito Público, São Paulo: Malheiros, n. 54, 2011. p. 198): "Questi interessi pubblici, colletivi dei quali i 'lamministrazione deve curare il soddisfacimento, non sono, si noti bene, semplicimente, I'interesse dell 'amministrazione intesa come apparato organizzativo, sebbene quello che è stato chiamato I'interesse colletivo primario, formato dal complesso degli interessi individuali prevalenti in una determinata organizzazione guiridica della collettivittà, mentre I'interesse dell 'apparato unitariamente considerato, sarebbe semplicemente uno degli interessi secondari che possono essere realizzati soltano in caso di coincidenza, e nei limiti di siffatta coincidenza con I'interesse colletivo primario" (ALESSI, Renato. Principi di Diritto Amministrativo, v. 1. Milano: Giuffrè, 1966. p. 200-201).

61 MARTINS, Ricardo Marcondes. Arbitragem e administração pública: contribuição para o sepultamento do tema, cit., p. 197-198.

62 MELLO, Celso Antônio Bandeira de. Curso de Direito Administrativo, cit., p. 65-66.

63 Quanto ao particular, cf., ainda: MARTINS, Ricardo Marcondes. Arbitragem e administração pública: contribuição para o sepultamento do tema, cit., p. 198.

64 MARTINS, Ricardo Marcondes. Arbitragem e administração pública: contribuição para o sepultamento do tema, cit., p. 198. 
os interesses patrimoniais da Administração, interesses secundários", dispondo, em geral, que quanto a esses interesses secundários "a Administração não gozaria de supremacia", mas "estaria numa posição de igualdade em relação aos administrados" 65 . Mas adverte que "a pressuposição de interesses públicos disponíveis decorre de um vício metodológico, de um vício de premissa teórica, da equívoca pressuposição de que a Administração pode assumir a posição jurídica de um particular e afastar-se do regime de direito público"66.

Muito embora essa compreensão pareça ter escapado ao próprio Alessi ${ }^{67}$, Martins considera que sua doutrina permite superar esse vício, na medida em que expõe que o "interesse público secundário só é reconhecido pelo Direito quando for coincidente com o interesse público primário"68. Nessa perspectiva, "não basta que o interesse secundário da Administração seja compatível com o primário, ele deve ser coincidente, quer dizer, ele deve ser igual ao primário"69. Enfim, o "interesse público secundário, enquanto interesse juridicamente reconhecido, não possui autonomia", precisamente porque "só é juridicamente acatado pelo ordenamento se for coincidente com o primário". Assim, "noutros termos, o interesse secundário será um interesse juridicamente reconhecido somente quando for também um interesse primário"70. Trata-se, conforme Martins, "de uma armadilha conceitual: a Administração só pode perseguir o interesse primário e, por isso, só pode perseguir o chamado interesse secundário quando este for interesse primário"71. Destarte, ou interesse secundário coincide com o interesse primário, qualificando-se, assim, como interesse público, ou não se trata de interesse público.

65 MARTINS, Ricardo Marcondes. Arbitragem e administração pública: contribuição para o sepultamento do tema, cit., p. 199.

66 MARTINS, Ricardo Marcondes. Arbitragem e administração pública: contribuição para o sepultamento do tema, cit., p. 200.

67 MARTINS, Ricardo Marcondes. Arbitragem e administração pública: contribuição para o sepultamento do tema, cit., p. 201.

68 MARTINS, Ricardo Marcondes. Arbitragem e administração pública: contribuição para o sepultamento do tema, cit., p. 200.

69 MARTINS, Ricardo Marcondes. Arbitragem e administração pública: contribuição para o sepultamento do tema, cit., p. 200-201.

70 MARTINS, Ricardo Marcondes. Arbitragem e administração pública: contribuição para o sepultamento do tema, cit., p. 201.

71 MARTINS, Ricardo Marcondes. Arbitragem e administração pública: contribuição para o sepultamento do tema, cit., p. 201. 
Por uma e outra razão, em nada se distinguem, quanto ao particular, as finalidades da atuação dos advogados públicos e dos membros do Ministério Público. Afinal, quando se têm em vista a interpretação e a aplicação do Direito, uns e outros devem procurar induzir, cada qual a seu modo, a efetiva realização dos direitos subjetivos individuais assegurados pelo ordenamento jurídicopositivo. Nesse campo, cumpre aos agentes estatais aplicar o Direito aos fatos administrativos, inclusive quando realizam o controle interno da juridicidade do agir administrativo, que é atividade típica de advocacia pública, na medida em que se instrumentaliza a partir da atuação dos procuradores nos âmbitos consultivo e contencioso. Essa sua atuação pode ser preventiva, quando realizada no contexto da tomada de posições em âmbito administrativo, notadamente quando estamos diante da revisão de posturas administrativas contrárias ao Direito (autotutela), própria da atividade de controle desempenhada pela Advocacia Pública em âmbito consultivo. Mas também deve ser desenvolvida no ambiente processual, quando verificarmos, em concreto, que a pretensão deduzida em juízo pelo poder público ou ato impugnado pelo postulante revela-se contrário ao Direito ${ }^{72}$.

Como expressa Romeu Felipe Bacellar Filho, "não é por outro motivo, senão para alcançar o interesse público, que a Administração Pública, antes de tudo, está presa ao princípio da legalidade" ${ }^{\text {7з }}$. O que se dá é que a legalidade se apresenta, conforme Bandeira de Mello, como decorrência natural do interesse público, bem como da sua indisponibilidade pela Administração ${ }^{74}$. Basta ver que esse professor paulista a conceituou, em seus escritos, como "interesse do Estado e da sociedade na observância da ordem jurídica estabelecida"75. Disso resulta que, sob a ótica da atuação da Administração Pública e de seus agentes, a realização do interesse público deve guardar irrestrita compatibilidade com o Direito, adequando-se, assim, aos ditames da legalidade administrativa.

72 O Ministério Público, por sua vez, só atua de forma curativa, em controle externo à atividade administrativa, porque a Constituição Ihe veda o exercício de atividade consultiva ("Art. 129. São funções institucionais do Ministério Público: [...] IX - exercer outras funções que Ihe forem conferidas, desde que compatíveis com sua finalidade, sendo-Ihe vedada a representação judicial e a consultoria jurídica de entidades públicas" (destaques pessoais). Retomarei esse ponto no Tópico 3.1.3 do Capítulo 3.

73 BACELLAR FILHO, Romeu Felipe. A noção jurídica de interesse público no Direito Administrativo Brasileiro, cit., p. 95.

74 MELLO, Celso Antônio Bandeira de. Curso de Direito Administrativo, cit., p. 75.

75 MELLO, Celso Antônio Bandeira de. Curso de Direito Administrativo, cit., p. 72. 


\section{REFERÊNCIAS DAS FONTES CITADAS}

ALESSI, Renato. Principi di Diritto Amministrativo, v. 1. Milano: Giuffrè, 1966.

ALESSI, Renato. Sistema instituzionale del diritto amministrativo italiano. 3. ed. Milão: Giuffrè, 1960. p. 197.

BACELLAR FILHO, Romeu Felipe. A noção jurídica de interesse público no direito administrativo brasileiro. In: BACELLAR FILHO, Romeu Felipe; HACHEM, Daniel Wunder (Coord.). Direito administrativo e interesse público: estudos em homenagem ao Professor Celso Antônio Bandeira de Mello. Belo Horizonte: Fórum, 2010.

BACELLAR FILHO, Romeu Felipe; HACHEM, Daniel Wunder (Coord.). Direito administrativo e interesse público: estudos em homenagem ao Professor Celso Antônio Bandeira de Mello. Belo Horizonte: Fórum, 2010.

BARROSO, Luís Roberto. Prefácio. In: SARMENTO, Daniel (Org.). Interesses públicos versus interesses privados: desconstruindo o princípio da supremacia do interesse público. Rio de Janeiro: Lumen Juris, 2005.

BEZNOS, Clovis. Aspectos jurídicos da indenização na desapropriação. Belo Horizonte: Fórum, 2010.

BEZNOS, Clovis. Procuradoria Geral do Estado e defesa dos interesses públicos. Revista de Direito Público, São Paulo: Revista dos Tribunais, ano 23, n. 93, jan./mar. 1990.

BOTTINI, Pierpaolo Cruz. A Justiça do Trabalho e a reforma do Judiciário. In: CHAVES, Luciano Athayde (Org.). Direito processual do trabalho: reforma a efetividade. São Paulo: LTr, 2007.

CANOTILHO, José Joaquim Gomes de; MOREIRA, Vital. Fundamentos da Constituição. Coimbra: Coimbra Editora, 1991.

DALLARI, Dalmo de Abreu. Elementos de Teoria Geral do Estado. 20. ed. São Paulo: Saraiva, 1998. p. 118.

DI PIETRO, Maria Sylvia Zanella. Direito Administrativo. 13. ed. São Paulo: Atlas, 2001.

DI PIETRO, Maria Sylvia. Advocacia Pública. Revista Jurídica da Procuradoria Geral do Município de São Paulo, São Paulo, n. 3, p. 11-30, dez 1996.

ENTERRÍA, EduardoGarcía de; FERNÁNDEZ,Tomás-Ramón.Curso del DerechoAdministrativo, vol. II. $11^{\text {a }}$ ed. Madri, Thomson Civitas, 2008. p. 48; apud MELLO, Celso Antônio Bandeira de. A 
noção jurídica de "interesse público". In: MELLO, Celso Antônio Bandeira de. Grandes temas de direito administrativo. São Paulo: Malheiros, 2010.

FIGUEIREDO, Lúcia Valle. Perspectivas do direito público. Belo Horizonte: Del Rey, 1995.

FIGUEIREDO, Lúcia Valle. Processo e procedimento administrativo. In: FIGUEIREDO, Lúcia Valle. Perspectivas do direito público. Belo Horizonte: Del Rey, 1995.

GRINOVER, Ada Pellegrini, DINAMARCO, Cândido Rangel; WATANABE, Kazuo (Coord.). Participação e processo. São Paulo: Revista dos Tribunais, 1988.

GUEDES, Jefferson Carús; SOUZA, Luciane Moessa de (Coord.). Advocacia de Estado: questões institucionais para a construção de um Estado de justiça. Belo Horizonte: Fórum, 2009.

JUSTEN FILHO, Marçal. Conceito de interesse público e a "personalização" do direito administrativo. Revista Trimestral de Direito Público, n. 26, 1999.

MADEIRA, Danilo Cruz. O papel da Advocacia Pública no Estado Democrático de Direito. Revista Virtual da AGU, ano 10, n. 107, dez. 2010. Disponível em: <http://www.agu. gov.br/sistemas/site/TemplateImagemTextoThumb.aspx?idConteudo $=152998 \& i d$ _ site $=1115 \&$ ordenacao $=1>$. Acesso em: 23 out. 2012.

MADUREIRA, Claudio. Advocacia Pública. Belo Horizonte: Fórum, 2015 (no prelo).

MADUREIRA, Claudio. Royalties de petróleo e Federação. Belo Horizonte: Fórum, 2012.

MARTINS, Ricardo Marcondes. Arbitragem e administração pública: contribuição para o sepultamento do tema. Revista Trimestral de Direito Público, São Paulo: Malheiros, n. 54, 2011.

MEDAUAR, Odete. O direito administrativo em evolução. São Paulo: Revista dos Tribunais, 1992.

MEIRELLES, Hely Lopes. Direito Administrativo Brasileiro. 16. ed. São Paulo: Revista dos Tribunais, 1991.

MELLO, Celso Antônio Bandeira de. A noção jurídica de "interesse público". In: MELLO, Celso Antônio Bandeira de. Grandes temas de direito administrativo. São Paulo: Malheiros, 2010.

MELLO, Celso Antônio Bandeira de. Curso de Direito Administrativo. 27. ed. São Paulo: Malheiros, 2010. 
MELLO, Celso Antônio Bandeira de. Grandes temas de direito administrativo. São Paulo: Malheiros, 2010.

MELLO, Celso Antônio Bandeira de. Legalidade, discricionariedade: seus limites e controle. In: MELLO, Celso Antônio Bandeira de. Grandes temas de direito administrativo. São Paulo: Malheiros, 2010.

ROCHA, Carmen Lúcia Antunes. O princípio constitucional da igualdade. Belo Horizonte: Lê, 1990.

ROCHA, Carmen Lúcia Antunes. Princípios constitucionais da Administração Pública. Belo Horizonte: Del Rey, 1994.

SARMENTO, Daniel (Org.). Interesses públicos versus interesses privados: desconstruindo o princípio da supremacia do interesse público. Rio de Janeiro: Lumen Juris, 2005.

SOUZA, Luciane Moessa de. Autonomia institucional da advocacia pública funcional de seus membros: instrumentos necessários para a concretização do Estado Democrático de Direito. In: GUEDES, Jefferson Carús; SOUZA, Luciane Moessa (Coord.). Advocacia de Estado: questões institucionais para a construção de um Estado de justiça. Belo Horizonte: Fórum, 2009.

SOUZA, Luciane Moessa de. Consultoria jurídica no exercício da advocacia pública: a prevenção como melhor instrumento para a concretização dos objetivos do Estado brasileiro. In: GUEDES, Jefferson Carús; SOUZA, Luciane Moessa de (Coord.). Advocacia de Estado: questões institucionais para a construção de um Estado de justiça. Belo Horizonte: Fórum, 2009.

VILANOVA, Lourival. Estruturas lógicas e o sistema de direito positivo. São Paulo: Noeses, 2005.

WATANABE, Kazuo. O acesso à justiça e a sociedade moderna. In: GRINOVER, Ada Pellegrini, DINAMARCO, Cândido Rangel; WATANABE, Kazuo (Coord.). Participação e processo. São Paulo: Revista dos Tribunais, 1988.

Recebido em: setembro/2015

Aprovado em: junho/2017 